\section{What is already known on this topic}

Service in the Gulf war is associated with an increased rate of reported symptoms and worsening subjective health

Post-combat syndromes have been described after most modern conflicts from the US civil war onwards

\section{What this study adds}

There seems to be no single post-combat syndrome but a number of variations on a theme

The ever changing form of post-combat syndromes seems to be related to advances in medical understanding, the developing nature of warfare, and cultural undercurrents

Because reported symptoms are subject to bias and changing emphasis related to advances in medical science or the discovery of new diseases, the characterisation of individual syndromes has to be treated with caution

Attributions by servicemen are generally consistent with symptom characteristics, though there seems to be a growing reluctance to consider the stress of military service as a cause

able pattern of normal responses to the physical and psychological stress of war, then it may be managed in a more effective manner.

Specialist advice was sought in cardiology from Drs Stephen Holmberg and Iqbal Malik, in gastroenterology from Dr Ian Forgacs and Sir Christopher Booth, in radiology from Drs
Michele Marshall, Erica Denton, and C N O'N Digges, and in medicine from Professor Harry Lee and Dr Roger Gabriel. The Department of Social Security provided access to the war pensions archive, and we thank Dr Elizabeth Braidwood, Jenny Robb, and Paul Griffiths. The Army Historical Branch helped with military sources.

Contributors: See bmj.com.

Funding: The study was funded by a grant from the US Army Medical Research and Materiel Command under grant DAMD17-98-1-8009. EJ was supported by a grant from the US Department of Defense.

Competing interests: None declared, except funding for EJ.

1 Unwin C, Blatchley N, Coker W, Ferry S, Hotopf M, Hull L, et al. Health of UK servicemen who served in Persian Gulf war. Lancet 1999;353:16978.

2 Ismail K, Everitt BS, Blatchley N, Hull L, Unwin C, David A, et al. Is there a Gulf war syndrome? Lancet 1999;353:179-89.

3 Doebbeling BN, Clarke WR, Watson D, Torner JC, Woolson RF, Voelker $\mathrm{MD}$, et al. Is there a Gulf war syndrome? Evidence from a large population-based survey of veterans and nondeployed controls. Am J Med 2000;108:695-704.

4 Haley RW, Thomas KL, Hom J. Is there a Gulf war syndrome? Searching for syndromes by factor analysis of symptoms. JAMA 1997;277:215-22, 278:388.

5 Everitt BS, Landau S, Leese M. Cluster analysis. London: Edward Arnold, 2001.

6 Tibshirani R, Walther G, Hastie T. Estimating the number of clusters in a data set via the gap statistic. JR Soc Stat 2001;63:411-23.

7 Grant RT. Observations on the after-histories of men suffering from the effort syndrome. Heart 1925;12:121-42.

8 Kang HK, Bullman TA. Mortality among US veterans of the Persian gulf war: 7-year follow up. Am J Epidemiol 2001;154:406-9.

9 Mitchell TJ, Smith GM. History of the great war based on official documents, medical services. London: HMSO, 1931:103, 315.

10 Langman MJS. The epidemiology of chronic digestive disease. London: Edward Arnold, 1979.

11 Tidy HL. Discussion on dyspepsia in the forces. Proc $R$ Soc Med 1941;34:21-36.

12 Bergman BP, Miller SAStJ. Unfit for further service: trends in medical discharge from the British army 1861-1998. J R Army Med Corps 2000; $146: 204-11$.

13 Shorter E. Paralysis-the rise and fall of a hysterical symptom.J Soc Hist 1986; $19: 549-82$

14 Shorter E. From paralysis to fatigue, a history of psychosomatic illness in the modern era. New York: Free Press, 1992.

(Accepted 3 January 2002)
Traumatic Stress Clinic, London W1T 4PL

Jane Herlihy

psychologist in clinical

training

Stuart Turner

consultant psychiatrist

University College,

University of

London, London

WC1E 6BT

Peter Scragg

lecturer in psychology

Correspondence to:

J Herlihy

jane@herlihyj.

freeserve.co.u

BMJ 2002;324:324-7

\title{
Discrepancies in autobiographical memories- implications for the assessment of asylum seekers: repeated interviews study
}

\author{
Jane Herlihy, Peter Scragg, Stuart Turner
}

\author{
Abstract \\ Objective To investigate the consistency of \\ autobiographical memory of people seeking asylum, \\ in light of the assumption that discrepancies in \\ asylum seekers' accounts of persecution mean that \\ they are fabricating their stories. \\ Design Repeated interviews. \\ Setting England, 1999 and 2000. \\ Participants Community sample of 27 Kosovan and \\ 12 Bosnian refugees. \\ Main outcome measures Discrepancies in repeated \\ descriptions of one traumatic and one non-traumatic \\ event, including specific details, rated as central or \\ peripheral to the event. Self report measures of \\ post-traumatic stress disorder and depression.
}

Results Discrepancies between an individual's accounts were common. For participants with high levels of post-traumatic stress, the number of discrepancies increased with length of time between interviews. More discrepancies occurred in details peripheral to the account than in details that were central to the account.

Conclusion The assumption that inconsistency of recall means that accounts have poor credibility is questionable. Discrepancies are likely to occur in repeated interviews. For refugees showing symptoms of high levels of post-traumatic stress, the length of the application process may also affect the number of discrepancies. Recall of details rated by the interviewee as peripheral to the account is more likely to be inconsistent than recall of details that are central 
to the account. Thus, such inconsistencies should not be relied on as indicating a lack of credibility.

\section{Introduction}

Under the terms of the 1951 United Nations convention on the status of refugees, a refugee is someone with a well founded fear of persecution on arbitrary grounds-such as ethnicity or political opinion-who cannot achieve protection in their home country. ${ }^{1}$ When they escape to a new country, their application for asylum is considered in the light of the information they can supply and any facts known about their country. There will often be little documentary evidence about the asylum seeker, and a legal decision on status by the authorities in the country of reception may rest on their credibility as a witness.

Asylum seekers sometimes give accounts of persecution that differ with each telling (that is, they contain discrepancies). A common, understandable assumption is that the case is not a credible one-that is, the account is false or exaggerated and that is why it cannot be recalled clearly. In the United Kingdom, national guidelines state that "discrepancies, exaggerated accounts, and the addition of new claims of mistreatment may affect credibility" and that such discrepancies may be used as a reason for refugees being refused asylum. ${ }^{2}$

Generally, the more detail a memory has, the more believable and convincing the account is. The gist of an autobiographical memory (central details) can be reconstructed from general (historical or schematic) knowledge, whereas details of a specific event (peripheral details) cannot. Recall of peripheral details is thus seen as a good way of distinguishing between "accurate recollection and plausible reconstruction." This is presumably the principle that, in part, guides state authorities' reliance on consistent details as an indication of credibility.

However, this view has been challenged in research on witnesses' evidence. Laboratory and field studies have shown that people recall more details that are central when an event has a high level of emotional impact, such as armed robbery, than when an event is emotionally neutral. Their recall of central details is, however, at the expense of their recall of peripheral details. ${ }^{4}$ Also, peripheral detail is more susceptible to disruption after the event. For example, discussions about the event $t^{5}$ and the exact wording of questions ${ }^{6}$ can change the detail of the responses given by the asylum seeker.

Emotional disorders can affect the quality of material that people remember. Clinical anxiety can lead to selective attention to threat, and depressed patients are biased towards recalling negative personal memories in favour of positive ones. ${ }^{7}$ Patients with depression and with post-traumatic stress disorder can have difficulties in retrieving specific autobiographical memories. $^{89}$ Refugees often present with clinical depression or with post-traumatic stress disorder. ${ }^{10-12}$

Where the experience is highly traumatic-for example, serious injury to the person-the situation may be even more complex. There may be important differences between traumatic and non-traumatic memories. For example, initial recall of traumatic events by people with post-traumatic stress disorder typically does not involve normal narrative memory. ${ }^{13}$ In a military population, inconsistent (discrepant) recall of traumatic experiences over time has been reported, ${ }^{14}$ with a notable correlation between symptoms of post-traumatic stress disorder and an increase in traumatic memories.

Our study explores empirically the consistency of recall of traumatic and non-traumatic events in a sample of refugees with no obvious motivation to fabricate accounts. Any inconsistencies found would require an alternative explanation. We hypothesised that there would be discrepancies between an individual's accounts, that the discrepancies would be exacerbated by symptoms of post-traumatic stress disorder, and that more discrepancies would occur in peripheral details than in central details.

\section{Methods}

We invited 27 Kosovan Albanians and 16 Bosnians to take part in research about memory; 23 were men and 20 were women, all aged between 18 and 64 (mean 39.5 (SD 14.5)). The research was not part of clinical treatment or medicolegal assessment. All participants had been granted leave to remain in the United Kingdom under the United Nations High Commissioner for Refugees group programmes - that is, none of the participants had given accounts of their experiences to gain their asylum status. We obtained written (translated) informed consent from all participants and the study was granted ethical approval.

One of us $(\mathrm{JH})$ interviewed all participants twice (with an interpreter). The time between interviews ranged from three to 32 weeks. At the first interview we used a translated form of the post-traumatic diagnostic scale to assess the level of post-traumatic stress. ${ }^{15}$ Participants were asked to recall a traumatic event from their experiences. Fifteen predefined questions were asked about the chosen event-for example, what was the date? Similar questions were asked about a non-traumatic event. After answering each question, participants were asked to rate that particular element as central or peripheral to their experience. At the second interview participants were asked to recall the same two events. The same 15 questions were repeated and we assessed whether the participants were depressed by using a translated form of the Beck depression inventory. ${ }^{16}$

\section{Calculation of discrepancy rates}

Discrepancy rates were calculated by dividing the number of discrepant details between answers at the two interviews (including new information) by the total number of units of information in the first interview. Four separate rates were calculated per participant: central details of traumatic memories, peripheral details of traumatic memories, central details of non-traumatic memories, and peripheral details of non-traumatic memories.

Another rater coded $70 \%$ of the transcripts according to written coding procedures. Intraclass correlation estimates for the four rates ranged from 0.65 to 0.81 . General linear model univariate analyses and bivariate correlations were used to compare the discrepancy rates of participants who scored high on the post-traumatic diagnostic scale with those of partici- 
Table 1 Variation between two accounts given by asylum seekers. Results are mean (range)

\begin{tabular}{lcc} 
& \multicolumn{2}{c}{ Discrepancy rate } \\
\cline { 2 - 3 } $\begin{array}{l}\text { Time between } \\
\text { interviews }\end{array}$ & $\begin{array}{c}\text { High post-traumatic } \\
\text { stress }\end{array}$ & $\begin{array}{c}\text { Low post-traumatic } \\
\text { stress }\end{array}$ \\
\hline Long $(>10$ weeks $)$ & $0.47(0.38-0.65)$ & $0.27(0.15-0.37)$ \\
\hline Short $(<10$ weeks $)$ & $0.25(0.09-0.40)$ & $0.28(0.01-0.50)$ \\
\hline
\end{tabular}

pants who scored low on the scale. General linear model repeated measures tests were used to analyse the interactions between the types of detail (central versus peripheral) and the type of event recalled (traumatic versus non-traumatic). SPSS software was used for all analyses.

\section{Results}

Four of the Bosnian participants left the study after the first interview. All participants reported traumatic experiences. Scores of symptom severity on the posttraumatic diagnostic scale (maximum 51) ranged from 5 to 50 (27.3 (10.9)). Participants were divided into high and low scorers: scores of $\geqslant 26$ were categorised as high $(\mathrm{n}=19)$; scores of $\leqslant 25$ were categorised as low $(\mathrm{n}=21)$. The depression scores (maximum 63), standardised to the Beck depression inventory II, ranged from 7 to 52 (mean 24.2 (11.6)). Of the 39 scores, 31 indicated probable clinical depression (score $>14$ ); 21 indicated moderate or severe depression.

The mean age of the Bosnian group was greater than that of the Kosovan group (46.2 $v 35.5$ years; $\mathrm{P}<0.05$, $\mathrm{t}$ test) and the average time between interviews was significantly longer for Bosnian refugees than for Kosovan refugees ( $159 v 29$ days; $\mathrm{P}<0.0001)$. No significant differences in psychopathology between the two groups were seen. To reduce the limitations of these differences on interpreting the results, and to take account of the loss of four subjects from the Bosnian group, each of the hypotheses was tested on the whole sample and then on the larger of the two subsets-the 27 Kosovan participants-alone. Significant findings only are reported.

\section{Discrepancies}

Discrepancies between the two accounts were found for all participants. The mean (overall) discrepancy rate was $0.32(0.14$; range $0.01-0.65 ; 95 \%$ confidence interval 0.28 to 0.36$)$.

The length of time between interviews had a significant effect on discrepancy rates. Testing for homogeneity of regression in the two groups (high or low levels of post-traumatic stress) showed an interaction between the level of post-traumatic stress and length of time between interviews. In the group with high post-traumatic stress there was a positive association between number of discrepancies and length of delay $(r=0.70, \mathrm{P}<0.01)$, but this difference was not seen in the group with low post-traumatic stress $(r=-0.122)$ (also see table 1). A univariate analysis of variance showed that this interaction was significant $\left(F_{1,32}=6.48, \mathrm{P}<0.05\right)$.

The distributions of the discrepancy rates for peripheral details were skewed because of three outliers; these values were excluded from the parametric analyses. We confirmed our findings including the outliers, using non-parametric tests.

The mean discrepancy rates for each category of discrepancy are shown in table 2. Significantly more discrepancies were observed in peripheral details than in central details $\left(F_{1,32}=5.06, \mathrm{P}<0.05\right)$. A Wilcoxon signed ranks test confirmed a significant difference between peripheral and central discrepancy rates $(z=2.31, \mathrm{P}<0.05)$.

The interaction between type of detail and type of event recalled was not significant. Retrospective pairwise comparisons showed that type of detail (central or peripheral) had a significant effect on the discrepancy rate when memories were traumatic $\left(F_{1,32}=4.42, \quad \mathrm{P}<0.05\right)$, but not when they were non-traumatic $\left(F_{1,32}=1.25, \mathrm{P}=0.27\right)$. This result was not replicated, however, with non-parametric testing (traumatic central versus traumatic peripheral discrepancies, $z=1.89, \mathrm{P}=0.06$; non-traumatic central versus non-traumatic peripheral discrepancies, $z=1.74$, $\mathrm{P}=0.08$ )

In the Kosovan subsample, more discrepancies were found in peripheral details than in central details (table 2). The main effect of type of detail (central or peripheral) was in the same direction as the whole sample and marginally significant $\left(F_{1,24}=4.25\right.$, $\mathrm{P}=0.05)$. This finding was not replicated with non-parametric testing $(z=1.34, \mathrm{P}=0.18)$.

\section{Discussion}

Discrepancies (including the provision of new information) exist between autobiographical accounts of refugees given by the same individual on two occasions up to seven months apart. These findings cannot be explained on the grounds of intent to deceive. For refugees with high post-traumatic stress disorder, more discrepancies were found with longer times between interviews. (In the asylum process, there may be months or years between the original interview and an appeal hearing.) In addition, more discrepancies are found in details rated by participants as peripheral, compared with recollection of the central gist of the event. Discrepancies therefore cannot be taken as automatically implying fabrication.

Our findings cause us to question why such discrepancies might exist. Our research cannot provide a causal explanation but it can point to some possibilities. A common difficulty reported was related to the experience of repeated events that are similar. This may have led to the recall of an event similar in type but different in detail at the second interview, or to the mixing up of two or more events. The emotional state of the refugee at the time of the interview may have

Table 2 Discrepancy rates $(n=36)$. Values are mean (SD) (95\% confidence intervals)

\begin{tabular}{lcccccc} 
& \multicolumn{2}{c}{ Traumatic memory } & & \multicolumn{2}{c}{ Non-traumatic memory } \\
\cline { 2 - 3 } Data & \multicolumn{2}{c}{ Central } & Peripheral & & Central & Peripheral \\
\hline Whole sample & $0.31(0.21)(0.23$ to 0.38$)$ & $0.42(0.33)(0.31$ to 0.54$)$ & & $0.28(0.19)(0.21$ to 0.34$)$ & $0.31(0.16)(0.26$ to 0.37$)$ \\
\hline Kosovan subsample & $0.25(0.14)(0.19$ to 0.31$)$ & $0.37(0.32)(0.24$ to 0.50$)$ & & $0.27(0.2)(0.19$ to 0.35$)$ & $0.33(0.21)(0.24$ to 0.42$)$ & $F_{1,32}=5.06, P<0.05$ \\
\hline
\end{tabular}


affected his or her responses. For example, one participant changed his description of his treatment by military police from "we were slapped around" to "we were badly beaten." He may simply have been in a different mood state in each interview, thus giving different evaluations of his experience. In states of depressed mood, recall is biased towards negative memories. ${ }^{7}$ Further studies should consider measuring the person's state of mood at each interview.

\section{Reminiscence}

Reminiscence is the phenomenon of new information about an event becoming available over repeated recall. It has been shown clearly in the laboratory but has received little interest in applied areas. One explanation for reminiscence is that, once a person has initiated a search in memory, the search continues. The person may or may not be consciously aware of the process. This may lead to the checking of memories with others who were present at the time, or the gradual remembering of more detail. Both these factors would be associated with discrepancies and may increase in importance over time.

\section{Length of time between interviews}

Although it was not hypothesised initially, and we must consider the possibility of type I error, the effect of the interaction of post-traumatic stress and length of time between interviews on discrepancies is probably the most important finding in relation to asylum policy. If discrepancies continue to be used as a criterion for regarding a case as lacking credibility, then asylum seekers who have post-traumatic stress at the time of their interviews are systematically more likely to be rejected the longer their application takes. Cogent reasons exist as to why memories may be different when a person has post-traumatic stress disorder ${ }^{13} 17$ and these certainly merit further exploration in the context of asylum applicants and refugees.

Our study shows the danger of concluding that asylum seekers are fabricating their histories, solely on the basis of discrepancies between interviews, even when the interviews are only weeks apart. Discrepancies are common, especially (although not exclusively) when the person has post-traumatic stress disorder and has to wait a long time between interviews. Discrepancies are more likely to arise when the details required are peripheral to the interviewee's experience and when the content is traumatic to the interviewee. All of these factors are present in many asylum applications, and they may be increasing the risk of incorrect judgments. Our study has important implications for national and international policy in the assessment of asylum seekers.

Boba Dobretic, Teuta Hoxha, and Dr Laidon Shapo gave cultural advice and interpreting and translation work. Dr Pasco Fearon was the statistical consultant.

Contributors: JH initiated the study, conducted the theoretical research, formulated the hypotheses, designed the protocol, and carried out the data collection, statistical analyses and interpretation of the results. ST proposed the original idea of investigating discrepancies, discussed design issues, gave access to participants, and was field supervisor for JH's doctoral thesis in clinical psychology at University College London. PS discussed design issues and core ideas and was UCL internal supervisor for the doctoral thesis. All three authors contributed to the writing of the paper.

Funding: University College London. This work was undertaken with the support of Camden and Islington Mental Health

\section{What is already known on this topic}

Discrepancies between accounts of an event are often used to judge the credibility of asylum seekers

\section{What this study adds}

Discrepancies arise between two accounts of the same event even when there is no reason for fabrication

Refugees with high levels of post-traumatic stress are more likely to give inconsistent accounts if they have a long time to wait between interviews

Interviewees are more likely to be inconsistent in details that they rate as peripheral to their experiences than details they consider to be central

Inconsistent recall does not necessarily imply that asylum seekers are fabricating their accounts

NHS Trust, who received funding from the NHS Executive; the views expressed in this publication are those of the authors and not necessarily those of the NHS executive or the Department of Health.

Competing interests: JH submitted the study in part fulfillment of JH's requirements for a doctorate in clinical psychology at University College London. ST undertakes medicolegal assessments of asylum seekers.

1 United Nations High Commission for Refugees. Handbook on procedures and criteria for determining refugee status. Geneva: United Nations High Commission for Refugees, 1992. www.unhcr.ch/ (accessed 31 Jul 2001)

2 Immigration and Nationality Directorate (UK). Assessing the claim London: Home Office, 1998. www.homeoffice.gov.uk/ (accessed Jul 2000)

3 Heuer F, Reisberg D. Emotion, arousal, and memory for detail. In: Christianson SA, ed. The handbook of emotion and memory: research and theory. Hillsdale NJ: Erlbaum, 1992:151-80.

4 Christianson SA, Safer MA. Emotional events and emotions in autobiographical memories. In: Rubin DC, ed. Remembering our past:studies in autobiographical memory. Cambridge: Cambridge University Press, ies in autobiog

5 Hollin CR, Clifford BR. Eyewitness testimony: the effects of discussion on recall accuracy and agreement. J Appl Soc Psychol 1983;13:234-44.

6 Lipton JP. On the psychology of eyewitness testimony. J Appl Psychol 1977;62:90-5.

7 Williams JMG, Watts F, MacLeod C, Mathews A. Cognitive psychology and emotional disorders. 2nd ed. Chichester: Wiley, 1997.

8 Williams JMG, Dritschel B. Emotional disturbance and the specificity of autobiographical memory. Cognition Emotion 1988;2:221-34.

9 McNally R, Litz B, Prassas A, Shin L, Weathers F. Emotional priming of autobiographical memory in post-traumatic stress disorder. Cognition Emotion 1994;8:351-67.

10 Van-Velsen C, Gorst-Unsworth C, Turner S. Survivors of torture and organized violence: demography and diagnosis. J Trauma Stress 1996:9:181-93.

11 Mollica RF, McInnes K, Sarajlic N, Lavelle J, Sarajlic I, Massagli MP. Disability associated with psychiatric comorbidity and health status in Bosnian refugees living in Croatia. JAMA 1999;282:433-9.

12 Smith-Fawzi MC, Murphy E, Pham T, Lin L, Poole C, Mollica RF. The validity of screening for post-traumatic stress disorder and major depression among Vietnamese former political prisoners. Acta Psychiatr Scand 1997;95:87-93.

13 Van der Kolk B, Fisler R. Dissociation and the fragmentary nature of traumatic memories: overview and exploratory study. J Trauma Stress 1995;8:505-25.

14 Southwick SM, Morgan III CA, Nicolaou AL, Charney DS. Consistency of memory for combat-related traumatic events in veterans of operation desert storm. Am J Psychiatry 1997;154:173-7.

15 Foa EB, Cashman L, Jaycox L, Perry K. The validation of a self-report measure of posttraumatic stress disorder: The Posttraumatic Diagnostic Scale. Psychol Assess 1997;9:445-51.

16 Beck AT. Beck Depression Inventory. 2nd ed. San Antonio: Harcourt Brace, 1996.

17 Brewin C, Dalgleish T, Joseph SA. Dual representation theory of posttraumatic stress disorder. Psychol Rev 1996;103:671-86.

(Accepted 13 September 2001) 